\title{
O desafio de construir novos significados para a pesquisa educacional
}

\section{Maria Carolina da Silva*}

COSTA, Marisa Vorraber; BUJES, Maria Isabel. Caminhos investigativos III: riscos e possibilidades de pesquisar nas fronteiras. Rio de Janeiro: DP\&A, 2005.

Repensar a prática de pesquisa na educação. Trilhar novos caminhos nas investigações educacionais. Problematizar as metodologias investigativas comumente usadas no campo da educação. Formular problemas diferentes. Questionar as categorias normalmente utilizadas para pensar a pesquisa educacional. Ampliar a noção de educação para além da escola. Produzir novos sentidos para o já estabelecido nas análises educacionais. Utilizar conceitos de áreas diversas para pensar as práticas na educação. Arriscar-se nas fronteiras, para pensar de outra forma. Essas são algumas das propostas do livro Caminhos investigativos III: riscos e possibilidades de pesquisas nas fronteiras, organizado por Marisa Vorraber Costa e Maria Isabel Bujes. Dando continuidade à série "Caminhos investigativos", que já conta com dois outros livros publicados, ${ }^{1}$ os dez textos que compõem a obra, embora discutam questões metodológicas na pesquisa em educação, fogem às prescrições. Parecem preferir apontar alguns caminhos, compartilhar dúvidas, multiplicar as perguntas e convidar à invenção e criação cotidiana de práticas diferenciadas de pesquisa, algo expresso em seu próprio título, no qual, em vez de se apresentar uma proposta única de metodologia opta-se pela expressão "caminhos

Mestranda em educação pela Faculdade de Educação da Universidade Federal de Minas Gerais. Membro do Grupo de Estudos e Pesquisas em Currículo e Culturas (GECC) da FaE UFMG. (Belo Horizonte/Brasil). mariacarolinasilva@hotmail.com.

1 Os dois títulos são: COSTA, Marisa Vorraber (Org.). Caminhos investigativos: novos olhares na pesquisa em educação. Rio de Janeiro: DP\&A, 2002; e COSTA, Marisa Vorraber (Org.). Caminhos investigativos II: outros modos de fazer e pensar pesquisa em educação. Rio de Janeiro: DP\&A, 2002. 
investigativos", caminhos esses que podem ser trilhados pelo/a pesquisador/a de formas diferenciadas.

Inseridos no contexto das pesquisas pós-críticas em educação, os textos que compõem a obra analisam o processo de construção de identidades e subjetividades na atualidade e as estratégias de governamento presentes em vários artefatos, questionam as redes de significado e os discursos que têm sido produzidos na e para a educação, discutem as políticas de representação e as características da cultura na contemporaneidade. Os artigos mostram que as pesquisas pós-críticas não têm como objetivo "descobrir a verdade", já que, nessa perspectiva, compreende-se que a verdade é construída pelos discursos e pelas relações de poder-saber que se constroem em determinada época. Nesse sentido, a pesquisa em educação não descobre a verdade sobre qualquer um dos problemas da atualidade; ela produz um discurso que, em função das relações de poder que se estabelecem na sociedade, pode vir a tornar-se verdadeiro. Sendo assim, as pesquisas pós-críticas rompem com uma visão que compreende a metodologia como forma de acessar a verdade, distinguindo-se, dessa forma, das pesquisas tradicionais, que procuravam na metodologia uma forma de garantir maior veracidade para a pesquisa.

Partindo desses princípios, Luiz Henrique Sacchi dos Santos, no primeiro capítulo, trata da construção da metodologia de pesquisa em que investigou as aulas de Ciências de um curso supletivo de ensino fundamental para trabalhadores metalúrgicos de Porto Alegre. Utilizandose da etnografia, o autor destaca que a "realidade" observada é construída pelo olhar do/a etnógrafo/a. Destaca também que é ele/a quem tem o direito (e o dever) de escrever sobre o que viu. A narrativa da pesquisa é sempre do/a pesquisador/a, o que significa que não há neutralidade, que os escritos serão marcados pela trajetória daquele que escreveu, por suas visões de mundo e concepções do que seja a cultura, a educação, os sujeitos da pesquisa, as teorias que o subsidiam. Por trabalhar com os estudos culturais, o autor considera que a metodologia de pesquisa deve se modificar ao longo do processo de investigação. Assim, mesmo que ele utilize prioritariamente as técnicas etnográficas, os pressupostos da análise de discurso também são usados para examinar o objeto de estudo em questão.

Como um filme (especificamente o filme Um amor quase perfeito) pode constituir-se em um artefato cultural bom para pensar algumas dimensões do processo de pesquisar? Essa é a questão que norteia o 
capítulo escrito por Dagmar Meyer e Rosângela Soares. As autoras estabelecem comparações entre o enredo do filme e aquilo que ocorre no processo de pesquisar: no início temos um problema, que suscita um uma investigação e que leva a respostas muitas vezes inesperadas; a busca por respostas é interessada e só pode ser feita de um lugar específico; nossas convicções podem nos impedir de ver outros aspectos. Porém, o que mais chama a atenção na leitura do texto é que tanto no filme como na pesquisa, o processo de investigação leva a uma mudança nos sujeitos: não somos os/as mesmos/as antes e depois da pesquisa. Partindo de referências pósestruturalistas, as autoras utilizam a metáfora da viagem para expressar o processo pelo qual passam as personagens do filme e para falar da atividade de pesquisa: uma viagem que ao invés de priorizar os pontos de chegada, focalizam "os processos e as práticas, sempre múltiplas e conflitantes, que vão conformando os - e se conformando - nos próprios caminhos investigativos" (p. 43).

Abordando especificamente o tema sugerido pelo subtítulo do livro, Maria Lúcia Wortmann destaca os trânsitos entre fronteiras disciplinares que tem estabelecido em suas pesquisas. A autora tem se dedicado a pensar o discurso científico na atualidade e, para isso, problematiza os conceitos científicos, utilizando-se de contribuições variadas: os estudos sobre filosofia da ciência, os estudos culturais, estudos literários etc. Nesse capítulo, ela narra especificamente um trabalho investigativo no qual procurou analisar como livros infanto-juvenis ensinam ao seu público o que é a natureza e a ciência. A autora destaca que a articulação de diferentes perspectivas de pesquisa tem riscos, porém os ganhos são muitos, já que na fronteira entre saberes "se produz uma gama variada de novas perguntas para as quais mesmo a estratégia articulatória, não oferece nenhuma garantia de solução" (p. 67).

Luís Henrique Sommer e Jociane Rosa de Macedo Costa discutem as mudanças que operaram em seus objetos de pesquisa com base nas leituras dos estudos culturais e de estudos foucaultianos. Em seu artigo, Sommer, que analisou um programa de informática educativa na cidade de Novo Hamburgo/RS, discute como seu problema de pesquisa passou de uma proposta da investigação da prática em escolas do município para uma análise do Projeto Agora, campanha jornalística que tinha como meta a popularização do computador e dos saberes da informática na cidade. Subjetivado pelos textos de Foucault, o autor lê esse material como uma estratégia de governamento da população de Novo Hamburgo. Já Jociane 
Costa mostra caminho semelhante. Partindo da sua inquietação ante a indefinição do papel da/o pedagoga/o, seu objeto inicial constituía-se na definição da identidade desse profissional. As leituras sobre identidade, porém, permitiram-lhe compreender que as identidades na atualidade são instáveis, mutáveis, fragmentadas. Assim, não faz sentido perguntar por uma identidade única de qualquer profissional. Focalizando, então, as políticas educacionais brasileiras e sua tentativa de fixar uma identidade para a/o pedagoga/o, a autora mostra como isso se vincula ao governamento tanto de profissionais como dos/as estudantes que estarão submetidos ao seu controle.

Já no capítulo "A escrita acadêmica: a arte de assinar o que se lê", Rosa Fischer defende que nossos textos acadêmicos aproximem-se da criação e da fruição estéticas. Além disso, a autora argumenta a favor da inscrição de nós mesmos em nossos textos. Partindo da constatação de que muitas vezes a paixão daquele que cria está ausente nos textos acadêmicos, uma leitura assinada (conceito que ela toma emprestado de Jacques Derrida) dos autores lidos é reivindicada pela autora. Assim, ela defende que, em vez de reduzir-se à mesmice de repetir o já dito, nossa leitura dos autores deve procurar buscar o ponto de contato entre os conceitos e nós mesmos. Diante das palavras de nossos autores devemos "dizer, escrever e pensar sobre aquilo que ali nos seduz, que nos faz vibrar, que nos encoraja a uma certa audácia de pensamento sobre o presente que vivemos" (p. 122). Fischer mostra que a escrita acadêmica está cheia de clichês, de uma verborréia incessante que faz com que muito do que é dito seja dispensável. Segundo ela, repetimos credos acadêmicos sem parar para refletir sobre o que eles dizem, sem que nosso texto esteja de fato investido naquilo que dizemos. Assim, ela sugere que devemos indagar cada página, cada apropriação, cada título, exercendo, dessa forma, uma técnica de si para uma escrita menos automática, sem perder de vista as leis que regem a escrita acadêmica. Ela ressalta que a proposta defendida não é a de que nossos textos devam, num passe de mágica, transformarse em literatura, mas sim que podemos entender a escrita acadêmica como "esse espaço que não se deixa apanhar por completo, que é luta, que é fuga do instituído, que jamais se torna forma fixa" (p. 131).

O que Sócrates e Descartes têm em comum que pode ser útil para pensar a pesquisa na atualidade? Essa é a questão que norteia o trabalho de Mauro Grün. Ele nos mostra como a dúvida constante está presente nesses dois autores, ponto que muitas vezes é esquecido na atualidade, 
na qual a resposta parece ter uma primazia em relação à pergunta. Considerando as diferentes críticas que são feitas aos dois pensadores (Sócrates por seu essencialismo e Descartes pela ênfase no método), o autor propõe não uma apropriação de todos os seus princípios, mas sim o retorno à pergunta. Descartes defende que o método da dúvida deve ser usado em alguns poucos momentos da vida. Grün apropria-se dessa idéia e questiona se o momento de escrita de teses e dissertações não seria aquele em que deveríamos nos utilizar desse método.

Quatorze categorias para pensar a cultura na atualidade são apontadas por Daniel Mato. O autor mostra a potencialidade de problematizações tais como: entender que a divisão entre cultura, economia, política e sociedade é meramente didática; centrar a análise nas práticas dos atores sociais; procurar compreender as redes transnacionais, locais e nacionais para compreender a cultura; diferenciar globalização de neoliberalismo e questionar a idéia de desterritorialização.

Fechando o livro, temos o artigo de Marisa Costa, que discute a "arte de perguntar". Tendo em vista que nossas escolhas e perguntas são sempre intencionais, a autora afirma que é "nossa radicalidade histórica que produz o tipo de perguntas que abala nossas certezas, que inquieta, que apaixona, que impulsiona e, muitas vezes, amedronta pelo que sugere como possibilidade" (p. 201). Partindo da análise do surgimento da educação e da pedagogia em seu estreito vínculo com o governamento de pessoas, Marisa Costa defende que a pesquisa educacional ainda é banhada pela concepção progressista e iluminista moderna. Isso implica que nossas perguntas costumam ser de cunho essencialista, procurando por uma resposta aplicável a todos os seres humanos. Porém, sabemos que na atualidade há várias vivências culturais, o que torna perguntas que busquem pela verdade (o que é mesmo a infância, a educação, a organização didática etc.) pouco úteis para compreensão dos problemas colocados à educação. Para a autora, o desafio dos/as pesquisadores/as de hoje consiste em "articular velhos temas em novos problemas" (p. 208). Assim, se o que pretendemos é contribuir para que aconteçam mudanças que consideramos necessárias "torna-se urgente e politicamente importante nos voltarmos para as contingências históricas, para as configurações singulares e variadas que assumem inúmeras questões, pois apenas sobre estas, é possível engendrar ações coletivas” (p. 209).

A discussão dos caminhos traçados nas pesquisas individuais, assim como discussões teóricas e políticas a respeito dos rumos da pesquisa na 
atualidade, marcam os trabalhos contidos no livro. Utilizando-se de conceitos dos estudos culturais e dos estudos pós-estruturalistas, essas pesquisas se propõem a pensar de formas diferenciadas os objetos, os problemas, as teorias e as metodologias de pesquisa em educação. Por acreditarem que a realidade é uma construção social, discursiva e permeada por relações de poder, esses estudos não procuram verdades, certezas e respostas únicas. Não podem, portanto, lançar mão das técnicas metodológicas já consagradas na pesquisa em educação, pois elas pouco ajudariam no processo de construção de novos significados para os problemas educacionais. Eles precisam justamente questionar essas metodologias, mostrando que a forma como elas usualmente são utilizadas precisam ser desconstruídas para que se possam produzir novos olhares na pesquisa.

Com o objetivo de "multiplicar e matizar a gama de olhares, desvencilhar-se da superioridade das certezas e contestar radicalmente a independência e a primazia do método" (p. 202), esse terceiro volume de Caminhos investigativos é mais do que um manual de pesquisa. Ele se propõe a problematizar, nos tempos incertos, fluidos, arriscados, híbridos em que vivemos, as categorias com as quais nos acostumamos a olhar o campo educacional. Nesse sentido, não seria interessante pensar em novos caminhos para a pesquisa educacional? Não seria enriquecedor tomar contato com uma obra que, com clareza, objetividade e fundamentação teórica, pode nos ajudar a dar as respostas urgentes que o nosso tempo nos exige? Não seria fundamental pensarmos de modo diferente daqueles que vimos pensando ao longo do tempo?

Caminhos investigativos III pode auxiliar na construção de novos significados para a educação, de novos traçados para as nossas pesquisas e de novas respostas para os problemas da sociedade contemporânea. Caminhemos, portanto, por esses novos caminhos investigativos.

Recebido em: 27/04/07

Aprovado em: 02/05/07 